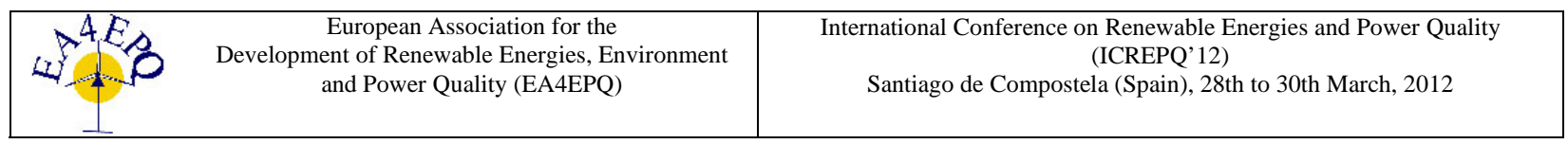

\title{
FLICKER EMISSION ANALYSIS OF A WIND FARM
}

\author{
${ }_{1}$ Elec. Eng. Diego Sebastián Giacosa Berriel, ${ }_{2}$ Elec. Eng. Gabriela Bonessi Menoni, \\ ${ }_{3}$ Elec. Eng. Tomás Di Lavello Mussi, ${ }_{4}$ Ind. Eng. Stud. Diego Nieves Martín.
}

${ }_{1}$ Engineer of Planning and Distribution Studies, UTE, dgiacosa@ute.com.uy, ${ }_{2}$ Engineer of Planning and Distribution Studies, UTE, gbonessi@ute.com.uy , 3 Manager of Planning and Distribution studies, UTE, dilavello@ute.com.uy, „4 Assistant of Planning and Distribution studies, UTE, dnieves@ute.com.uy

Administración Nacional de Usinas y Trasmisiones Eléctricas (UTE),
\[ \begin{array}{ll}\text { Address: } & \text { Paraguay 2431 Of. } 533 \\ \text { City: } & \text { Montevideo } \\ \text { Zip code: } & 11800 \\ \text { Country: } & \text { República Oriental del Uruguay } \\ \text { Phone: } & +598-22033758\end{array} \]

\begin{abstract}
In this paper is presented the criteria used by UTE, with respect to the Flicker emission of power plants; considering that this is one of the quality parameters monitored at the connection node.

This work is focused in the flicker emission phenomenon. It sets out the criteria used to determine the emission limits for individual users connected to the distribution network. Additionally it presents a theoretical method, based on international standards, to estimate the total emission of flicker that will produce a wind farm in the connection node.

The aim of this paper is to compare the theoretical emission flicker, with the field measurements in the connection node of a power generator. Here are calculated individual emission limits and the theoretical estimation of the flicker emission from a wind farm of $10 \mathrm{MW}$ connected to a network of $31.5 \mathrm{kV}$.

Finally, these values are compared with $\mathrm{P}_{\mathrm{st}}$ and $\mathrm{P}_{\mathrm{lt}}$ parameters, short-term flicker disturbance factor and long-term flicker disturbance factor of the installation of wind turbines, which arise from a registry conducted in the field, with real data measured in the connection node of the wind farm.
\end{abstract}

\section{Key words}

Flicker Emission, Distributed Generation, Wind Farm, Power Quality, Field Test.

\section{Abbreviations and definitions}

$\mathrm{HV}: \quad$ as defined in [2]

EHV: $\quad$ as defined in [2]

LV: $\quad$ as defined in [2]

MV: $\quad$ as defined in [2]
$\mathrm{P}_{\mathrm{lt}}$ : $\quad$ Flicker severity indicator of long duration.

$\mathrm{P}_{\mathrm{st}}: \quad$ Flicker severity indicator of short duration.

ST: Sub-transmission. Voltage level defined for the Uruguayan electrical system, corresponding to voltages of $31.5 \mathrm{kV}$ and $63 \mathrm{kV}$.

UTE: Administración Nacional de Usinas y Trasmisiones Eléctricas

\section{Introduction}

Uruguay has begun recently with electric energy generation from unconventional renewable energy sources. Within these renewable sources, it is remarkable the connection of Wind Farms to the electric system in the distribution network level, with voltages like $63 \mathrm{kV}$ and $31.5 \mathrm{kV}$. The entry into production from many of this Wind Farms recently, as well as the projected growing of installed wind power base, leads to a deeper study of the impact of disturbances produced by the wind turbine in the network connection node.

These studies are of utmost importance for the UTE, since the company is committed to its customers to preserve their power quality. This implies keeping control of different electric power parameters.

Note that UTE is the only national company that performs the transmission and distribution activities, and 
besides UTE there are various public and private agents that perform the generation activity.

\section{Development}

\section{A. Distributor's Requirements}

It is requested to Power Plants that use as a primary source wind energy supply the Study of Impact on Product Quality according to [1]. This study contains the calculation of the relative variations of voltage due to individual connection of the turbines and the calculation of the Flicker emission levels due to connection and continuous operation of the plant. The results of the previous study must comply with the limits calculated by the Distributor as indicated in [2].

It is also requested to the Producer the making of the testing for entry into service within which requires a record of power quality parameters.

The Producer shall determine a period of one week in which is recorded, in the connection node, the measure of harmonics of current, flicker and all the events such as voltage sags. During the measurement period must be registered some inputs and outputs of the generating plant in order to assess the impact of these events on the network.

For such measures are adopted the recommendations in [4]. The measuring equipment installed must register every 10 minutes Flicker severity indicators of short duration $\left(\mathrm{P}_{\mathrm{st}}\right)$ and long-term $\left(\mathrm{P}_{\mathrm{lt}}\right)$ and must meet the requirements according to [3].

The emission levels of Flicker are considered acceptable if $95 \%$ of the values obtained for the corresponding indicators do not exceed the limits specified in [2].

\section{B. Calculation of the Planning Limits}

The flicker emission levels produced by the fluctuating installations (loads and generation facilities) which are connected to the network, should not exceed under any circumstances the Compatibility Levels set out in [2] for $\mathrm{HV}$ and MV networks:

\section{Table I}

\begin{tabular}{|c|c|}
\hline \multicolumn{2}{|c|}{ Compatibility Levels for LV } \\
\hline $\mathrm{P}_{\mathrm{st}}$ & 1.0 \\
\hline $\mathrm{P}_{\mathrm{lt}}$ & 0.8 \\
\hline
\end{tabular}

The standard [2] also proposes the Planning Levels, which are used for purposes of assessing the impacts that cause floating facilities in the electrical system. The limits proposed by the standard are:

Table II

\begin{tabular}{|c|c|c|}
\hline \multicolumn{3}{|c|}{ Planning Levels } \\
\hline & MV & HV-EHV \\
\hline $\mathrm{P}_{\mathrm{st}}$ & 0.9 & 0.8 \\
\hline $\mathrm{P}_{\mathrm{lt}}$ & 0.7 & 0.6 \\
\hline
\end{tabular}

For the case considered, the levels that correspond to ST are the ones for $\mathrm{HV}$ (voltages greater than $35 \mathrm{kV}$ ). It is assumed that the voltage level $31.5 \mathrm{kV}$ also corresponds to $\mathrm{HV}$, as stated in [2], which states that the system function is more important than its nominal voltage when determining planning levels. Since the function of the ST network is the same of HV network, it is assumed equal levels for both ST and HV network.

Based on these Planning Levels can be set Global Emission Levels to be shared between the fluctuating installations.

The Global Emission Levels for ST are determined as follows:

$$
\begin{aligned}
G_{P s t H V} & =\sqrt[3]{L_{P s t H V}^{3}-T_{P s t E H V-H V}^{3} \times G_{P s t E H V}^{3}} \\
G_{P l t H V} & =\sqrt[3]{L_{P l t H V}^{3}-T_{P l t E H V-H V}^{3} \times G_{P l t E H V}^{3}}
\end{aligned}
$$

Where:

$\mathrm{G}_{\mathrm{PstHV}}$ is the maximum global contribution to the flicker level of all the HV fluctuating installations that can be connected to the considered system in terms of $\mathrm{P}_{\mathrm{st}}$.

$\mathrm{G}_{\mathrm{PltHV}}$ is the maximum global contribution to the flicker level of all the HV fluctuating installations that can be connected to the considered system in terms of $\mathrm{P}_{\mathrm{lt}}$.

$\mathrm{L}_{\mathrm{PstHV}}$ is the planning level for flicker $\left(\mathrm{P}_{\mathrm{st}}\right)$ in the HV system.

$\mathrm{L}_{\mathrm{PltHV}}$ is the planning level for flicker $\left(\mathrm{P}_{\mathrm{lt}}\right)$ in the HV system.

$\mathrm{G}_{\text {PstEHV }}$ is the maximum global contribution to the flicker level of all the EHV fluctuating installations that can be connected to the considered system in terms of $\mathrm{P}_{\mathrm{st}}$.

$\mathrm{G}_{\text {PltEHV }}$ is the maximum global contribution to the flicker level of all the EHV fluctuating installations that can be connected to the considered system in terms of $\mathrm{P}_{\mathrm{lt}}$.

$\mathrm{T}_{\text {PstEHV-HV }}$ is the transfer coefficient of flicker $\left(\mathrm{P}_{\mathrm{st}}\right)$ from EHV system to HV system.

$\mathrm{T}_{\text {PltEHV-HV }}$ is the transfer coefficient of flicker $\left(\mathrm{P}_{\mathrm{lt}}\right)$ from EHV system to HV system.

Considering the Planning Levels and a typical transfer coefficient of 0.8 yields the following Global Emission Levels for fluctuating installations connected in $\mathrm{HV}$ : 
Table III: Global Emission Levels for HV

\begin{tabular}{|c|c|}
\hline $\mathrm{G}_{\mathrm{PstHV}}$ & $\mathrm{G}_{\mathrm{PltHV}}$ \\
\hline 0.63 & 0.47 \\
\hline
\end{tabular}

These are the limits to be used to compare with the record of one week of the commissioning tests to be delivered by the Producer to UTE.

From these values can be determined the Individual Emission Limits for customers connected to the HV system; sharing the Global Emission Limits among these different customers according to their agreed power with UTE.

$$
\begin{aligned}
& E_{P s t i}=G_{P s t H V} \sqrt[3]{\frac{S_{i}}{S_{t H V}}} \\
& E_{P l t i}=G_{P l t H V} \sqrt[3]{\frac{S_{i}}{S_{t H V}}}
\end{aligned}
$$

Where:

$S_{i} \quad$ is the agreed power of the customer installation i (either load or generation).

$S_{t H V} \quad$ is total supply capacity of $\mathrm{HV}$ system including provision for future load growth.

These are the limits used by the Producer to compare with the theoretical calculation for flicker emission included in the Study of Impact on Product Quality.

For some cases of fluctuating installations with minor powers, are set minimum values for the Individual Emission Limits called Basic Levels Emissions.

$$
\begin{aligned}
& \mathrm{E}_{\text {Psti }}=0.35 \\
& \mathrm{E}_{\text {Plti }}=0.25
\end{aligned}
$$

These are the lower limits for flicker emission to be required to the Producer.

\section{Calculation of Flicker Emission Levels}

Described below are the theoretical calculations of the flicker emission levels to be included in the Study of Impact on Product Quality.

The flicker emission of one wind turbine is estimated according:

$$
P s t=P l t=c\left(\psi_{k}, v_{a}\right) \cdot \frac{S_{n}}{S_{k}}
$$

Where:

$c\left(\psi_{k}, v_{a}\right) \quad$ is the flicker coefficient of the wind turbine for the given network impedance phase angle at the connection node $\left(\psi_{k}\right)$ and for the given annual average speed at hub-height of the wind turbine $\left(v_{a}\right)$.

These coefficients are provided by the manufacturer through a test report, which contains the results of the measures described in [1].

$S_{n} \quad$ is the rated apparent power of the wind turbine.

$S_{k} \quad$ is the short-circuit apparent power at the connection node.

In the case of several wind turbines connected to the same connection node, the flicker emission levels may be estimated based on the following equation:

$$
P_{s t \Sigma}=P_{l t \Sigma}=\frac{1}{S_{k}} \cdot \sqrt{\sum_{i=1}^{N_{w t}}\left(c_{i}\left(\psi_{k}, v_{a}\right) \cdot S_{n, i}\right)^{2}}
$$

Where:

$C_{i}\left(\psi_{k}, v_{a}\right)$ is the flicker coefficient of the individual wind turbine.

$S_{n, i} \quad$ is the rated apparent power of the individual wind turbine.

$N_{w t} \quad$ is the number of wind turbines connected to the connection node.

In case of $n$ identical wind turbines, the above expression remains as follows:

$$
\text { Pst }=P l t=\sqrt{n} \cdot c\left(\psi_{k}, v_{a}\right) \cdot \frac{S_{n}}{S_{k}}
$$

D. Estimating the flicker level of the grid after the entry into service of the wind farm

Part of the aim of this paper is to estimate flicker emission levels in the connection node that there will be after the entry into service of the wind farm and thus predict future network problems, such as excessive emission levels.

This assumption is done from a record of the emission levels in the connection node before the entry of the park into service and the estimated emission levels of it, according to the equation (6).

In [2] is provided that a valid relation for combining flicker emissions from different sources is:

$$
P s t=\sqrt[\alpha]{\sum_{j} P s t_{j}^{\alpha}}
$$


A similar relation is valid for the parameter $\mathrm{P}_{\mathrm{lt}}$. The coefficient $\alpha$ generally depends on the emission source and in cases where it is not possible to justify the use of another value, it is taken equal to 3 . Under these considerations, the relation that is used for the estimation is:

$$
P s t=\sqrt[3]{\sum_{j} P s t_{j}^{3}}
$$

\section{Application}

Following is an application of the concepts shown above for the case of a 10MW wind farm connected to the ST grid, in the $31.5 \mathrm{kV}$ voltage level.

\section{A. Analysis of the registry with generation.}

From the registry of one week made in the connection node with the wind farm working is shown the compliance with of the Distributor's requirements. For simplicity, because it is a three-phase system, the $\mathrm{P}_{\mathrm{st}}$ and $\mathrm{P}_{\mathrm{lt}}$ values shown in this calculation and in the following correspond to the average value of the three phases.

With the data obtained it is performed the following cumulative percentage graphs for the values of the indicators of severity of flicker of short and long term:

Cumulative percentage

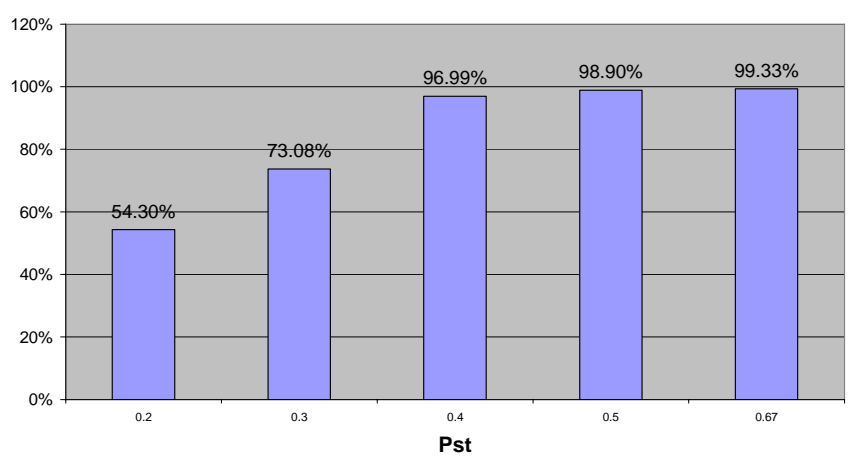

(a)

Cumulative percentage

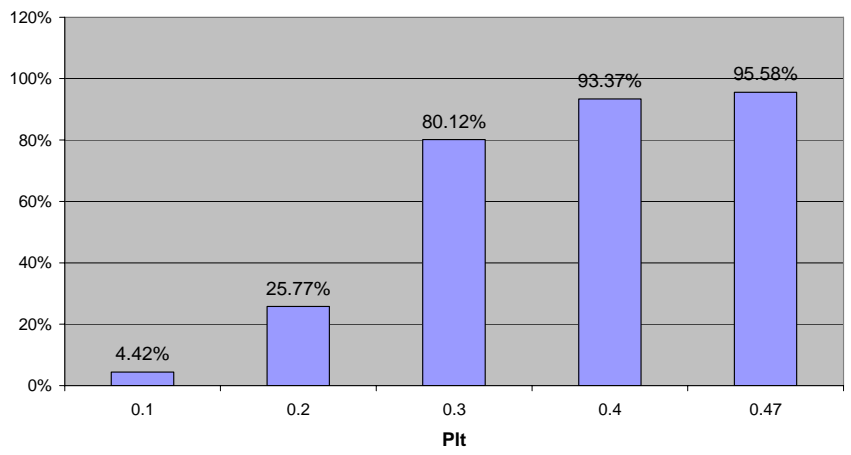

(b)

Fig. 1: Graphs of cumulative percentage for (a) $P_{\text {st }}$ and (b) $P_{l t}$
It is observed that $99.4 \%$ of $\mathrm{P}_{\mathrm{st}}$ values are below 0.63 , and $96.3 \%$ of $P_{l t}$ values are below 0.47 . It is also observed that over $95 \%$ of $\mathrm{P}_{\mathrm{st}}$ and $\mathrm{P}_{\mathrm{lt}}$ values are below the Global Emission Levels, in this way the wind farm accomplishes the Distributor's requirements.

\section{B. Calculation of individual emission limits.}

Given the global emission levels in the connection node calculated as indicated in numeral 2 of "Development", the installed power of wind farm and the power of customers directly connected to the ST grid, below is shown the calculation of the Individual Emission Limits according to the equations (3) and (4).

The following simplified electric diagram shows the fluctuating installations involved in this calculation:

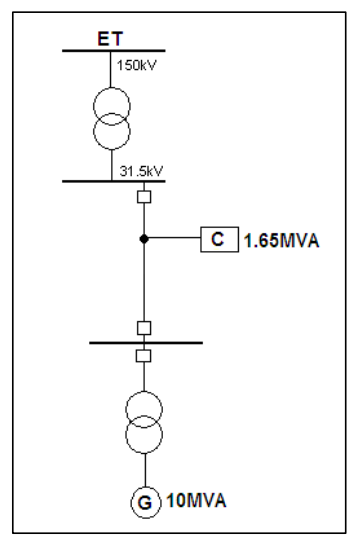

Fig. 2: Simplified electric diagram of the network studied.

The network parameters are:

- Total power of the fluctuating installations directly connected to HV system:

$$
S_{t H V}=11.65 M V A
$$

- Wind farm power: $S=10 \mathrm{MVA}$

- Global emission levels:

$$
G_{P s t H V}=0.63 \text { and } G_{P l t H V}=0.47
$$

According to equations (3) and (4), the Individual Emission Levels for the studied wind farm are:

$$
\begin{aligned}
& E_{P s t}=0.63 \times \sqrt{\frac{10}{11.65}}=0.60 \\
& E_{P s t}=0.47 \times \sqrt{\frac{10}{11.65}}=0.45
\end{aligned}
$$

Note that the individual emission is distributed according to the power of the customer installation, i.e. installations with more power have higher emission limits. 


\section{Theoretical estimation of the emission levels of a wind farm}

Below is the calculation of the estimated flicker emission levels of the wind farm studied under conditions of continuous operation, and which generating units are all identical. The values for this case are:

- $\quad$ Apparent power of each unit: $S_{N}=2001 k V A$

- Short-circuit apparent power in the connection node:

$S_{k}=93000 k V A$

- Flicker coefficient:

$$
c\left(\psi_{k}, v_{a}\right)=c\left(71^{\circ}, 8 \mathrm{~m} / \mathrm{s}\right)=2.1
$$

- Number of generating units: $n=5$

According to equation (7), the flicker emission levels of the wind farm are:

$$
P s t_{\text {Wind Farm }}=P l t_{\text {Wind Farm }}=\sqrt{5} \times 2.1 \times \frac{2001}{93000}=0.10
$$

It is seen that the theoretical estimate of the flicker emission of the wind farm is less than the emission limits established by the Distributor.

\section{Comparison of the theoretical emission with the registered values.}

From field measurements are obtained, in the first place, the mean values of the flicker levels prior to the entry into service of the wind farm. Using equation (9), these values are added to the estimated values obtained in the previous numeral. This result is compared with the flicker levels measured in the connection node with the wind farm in service.

To registry's values studied and under conditions in which the wind farm is not generating, the following values of $\mathrm{P}_{\mathrm{st}}$ and $\mathrm{P}_{\mathrm{lt}}$ parameters are obtained (considering the average of the three phases):

\begin{tabular}{|c|c|}
\hline $\mathbf{P}_{\text {st }}$ without generation & $\mathbf{P}_{\mathrm{lt}}$ without generation \\
\hline 0.21 & 0.27 \\
\hline
\end{tabular}

The previous values added with those values calculated in the previous numeral according to equation (9) are:

\begin{tabular}{|c|c|}
\hline \multicolumn{2}{|c|}{ Estimations with generation } \\
\hline $\mathbf{P}_{\text {st }}$ & $\mathbf{P}_{\mathbf{l t}}$ \\
\hline 0.24 & 0.29 \\
\hline
\end{tabular}

From the registry made with the wind farm operating arise the following values of Pst and Plt:

\begin{tabular}{|c|c|}
\hline $\mathbf{P}_{\text {st }}$ with generation & $\mathbf{P}_{\mathrm{lt}}$ with generation \\
\hline 0.23 & 0.32 \\
\hline
\end{tabular}

It is noted that the estimate of the emission of the wind farm reasonably adjusts to the measured data in the connection node.

\section{Conclusions}

It is verified the compliance with UTE's flicker requirement in the connection node of the ST system for the case of study.

For this case it is also verified that the theoretically estimated values $\mathrm{P}_{\mathrm{st}}$ and $\mathrm{P}_{\mathrm{lt}}$ are in compliance with the individual emission limits calculated.

Finally, it is proposed a method by which, from field measurements of flicker severity indicators in the connection node prior to the entry into service of the wind farm and the theoretical emission estimation can be obtained flicker levels that would have into the connection node with the wind farm in service.

This method is verified for a particular case, comparing the obtained results with the measurements of a registry made in field with the wind farm in service.

\section{References}

[1] IEC 61400-21, Measurement and assessment of power quality characteristics of grid connected wind turbines.

[2] IEC 61000-3-7, Assessment of emission limits for the connection of fluctuating installations to $\mathrm{MV}, \mathrm{HV}$ and $\mathrm{EHV}$ power systems.

[3] IEC 61000-4-15, Testing and measurement techniques Flickermeter - Functional and design specifications.

[4] IEC 61000-4-30, Testing and measurement techniques Power quality measurement methods. 


\section{Authors}

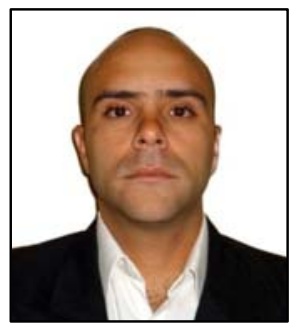

Electrical Engineer, born in Montevideo, Uruguay on February 23, 1979. Graduated from the University of the Republic, UDELAR (2008). He serves on the Management of Planning and Distribution Studies of UTE since January 2009. Since then he studies Power Centrals connectivity to the Subtransmission network and assists in the preparation of the Operating Agreements for the purchase of energy generated from renewable sources. (dgiacosa@ute.com.uy)

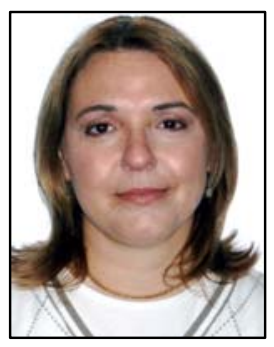

Gabriela Bonessi, Electrical Engineer, Power option, born in Salto, Uruguay, on September 18, 1972. Graduated from the Universidad de la República, UDELAR (2004). She currently serves on the unit of Planning and Research Management Distribution of UTE as engineer. Within UTE, involved in the studies of insertion of distributed generation in distribution network and developing the Operating Agreements signed between the Distributed Generator and UTE. (gbonessi@ute.com.uy)

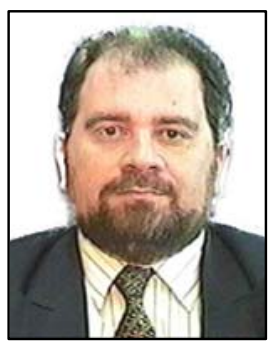

Tomás Dilavello, Industrial Engineer - Power Option, born in Montevideo, Uruguay on March 1, 1960. Graduated from the Universidad de la República, UDELAR (1984). He works on the unit of Planning and Research Management Distribution of UTE as Manager - April 1997 to date. His functions include planning for 31.5 and $63 \mathrm{kV}$ networks, is responsible for calculating the Distribution Energy Balance (Loss), Distributed Generation and studies to determine the remuneration of the distribution and regulatory issues related to distribution. Is a professor grade 3 at the Universidad de la República, Faculty of Engineering, regarding facilities Medium Voltage (MV substations). He joined the "Proyecto de Desarrollo Tecnológico" (PDT) on behalf of the University and UTE on the installation of distributed generation in Uruguay. (DiLavello@ute.com.uy)

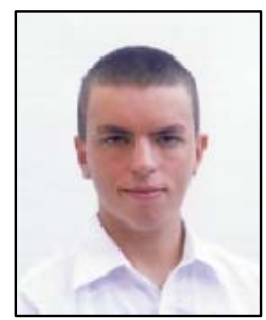

Diego Nieves, Industrial Engineering student profile materials and mechanical design, born in Montevideo, Uruguay, on 04 February 1987. He currently serves as Assistant Engineer in Management Studies and Planning Distribution of UTE. He assists in studies of power quality registries and confection connection agreements between producers and

UTE. (dnieves@ute.com.uy) 